\title{
Social Media and Counter-Democracy: The Contingences of Participation
}

\author{
Peter Dahlgren \\ Dept. of Communication and Media, Box 201, Lund University, 22100 Lund, Sweden \\ Peter.Dahlgren@kom.lu.se
}

\begin{abstract}
As democracy goes through various crisis and citizens increasingly disengage with traditional party politics, extra-parliamentarian, alternative modes of democratic politics emerge on many fronts; manifesting a development towards what is called counter-democracy. Debates on the role of the internet in democracy have been with us since its inception; today the discussions focus on social media, which have quickly emerged as public sphere sites and tools for democratic participation. My argument rests on the notion of contingency: the factors that make a phenomenon possible but also that delimit it. In this presentation I look at some key contingencies of political economy, technology, and socio-cultural patterns and how they impact on the spaces of online participation and the forms of identity that they foster. In particular I note the emergence of what I call the solo sphere as a mode of participation that has debilitating consequences for alternative politics.
\end{abstract}

Keywords: social media, political participation, counter-democracy, web environment, civic engagement.

\section{Introduction}

Democracy finds itself in difficult times, its perennial problems now exacerbated by severe economic and social crises that further challenge its institutions. Meanwhile, the media landscape is in rapid transition, evoking both despair and hope from various quarters. Social media have quickly emerged as public sphere sites and tools for democratic participation, and some observers assert the positive role that these media can play, while others are less sanguine. These discussions continue the lines of pessimism and optimism that have been with us in the debates since the internet was hailed as a major democratic asset when it emerged as a mass phenomenon in the mid-1990's. In this presentation I underscore the positive potential of social media in this regard, but my main focus to analytically problematise that which can hinder them from playing a democratically progressive role.

My argument rests on the notion of contingency: we have to examine not only the factors that make a phenomenon possible in a given set of circumstances, but also those that shape and delimit it. Thus, we have to look more broadly at the conditions and circumstances that impinge on political participation via social media. These may not always be readily visible, yet nonetheless are crucial in forming the character of 
such participation. I will be looking at some of the political economic realities behind the digital spaces of social media, as well as socio-cultural patterns social media use and the web environment in which they are embedded. In the earlier debates about the internet and the public sphere, as well as the current ones centering on social media, we should not expect to arrive at an ultimate, universally valid evaluation, be it positive or negative. Rather, we need to actively keep in our sights these questions, and strive for provisional conclusions in concrete, ever-shifting circumstances.

The political economy and formal architecture of the web are in a sense invisible to us even as we are aware of their presence. They impact in subtle ways on the conditions and consequences of participation. In particular we should note the commercial logic, the algorithm of the search engines that sluice us towards certain sets of websites rather than others, the vast accumulation and selling of personal information, the centralized ownership of information. More subtle perhaps are the socio-cultural currents, the overall 'normal drift' in the meanings and affects of political import - especially in regard to the economic system - that circulate in society and not least in social media. These currents largely flow in neoliberal directions, and can readily carry us away from politics and the political, away from public spheres, and towards individualised consumerism, entertainment, and sociality, subverting the drive for alternative politics. Our identities as citizens become subsumed under our self-perception as privatized consumers, and feelings of disempowerment and cynicism can readily emerge. Moreover, these discursive motifs are played out not just at the level of formal ideas, but also at the level of affect and experience, of subject positions. Navigating these waters requires accurate charts and a constant monitoring of our course.

In the following section 1 very briefly sketch some of the key dilemmas facing democracy, as a scene-setting for the discussion to follow. From there, in section 3, I enter into the conceptual terrain of social media in the context of democracy, and the debates around this theme.. This is followed, in section 4, with a short discussion about the concept of participation, which is at once an obvious term, but can also prove to be quite slippery. The two sections that follow (5-6) deal, in turn, with the reefs, and currents. I offer a short conclusion in section 8 .

\section{Troubling Times for Democracy}

Democracy is not a universal or static phenomenon, since its specific character varies under different and evolving circumstances. Its vitality, its functionality, and indeed its very survival, cannot be taken for granted. It is an historical project, criss-crossed by contestations between those forces that would in various ways constrict it and those who seek to broaden and deepen it, not least by enhancing participation. Even on the Left there is a variety of different visions of its future; see for example, Agamben et. al. [1]. A major problem today for participation (and democracy generally) is the tendency for accountable political power to drift away from the formal political system under the onslaught of neoliberal versions of societal development; see, for example, Harvey [2] and Harvey [3]; Fisher [4]; this not only 
subverts democracy, but leaves social devastation in its wake (Bauman [5]). When market dynamics come to be seen as the most suitable path towards a better future, democracy and the opportunities for meaningful civic participation become eroded. Many established normative frameworks are subverted, as market values seep into and put price tags on just about all areas of human life (Sandel [6]. Thus, neoliberalism has became not just a polity horizon but also a socio-cultural motif, shaping social relationships and visions of the good society. These themes have given rise to an extensive literature; see for instance Couldry [7]; Lewis [8] Young [9]. Bauman, in his extensive writings about the contemporary world, weaves together political, economic, social, and cultural strands in his analysis of what he calls liquid modernity; see for example, Bauman [10].

Even in the wake of the global crisis of 2008-9, there has been no serious rethinking of this paradigm or any effort to reform the international finance system among the power elites (Crouch [11]). At the same time, governments at all levels have decreasing margins of manoeuvrability in the context of increasingly complex globalisation. This in turn means that within nation states and local political units the practical requirements of governance become hampered, which can set further limits to what can be accomplished within democratic systems - and thus lead to more measures to restrain effective participation.

The upshot of these trends is the growing dilemmas that Western democracies have been facing over the past 20 years; democracy is being transformed as its social, cultural, and political foundations evolve, and the character of participation is a part of these large developments. There has been a growing literature on how citizens are apparently disengaging from the political system, coupled with feelings of powerlessness and cynicism towards the power elites. There is a growing erosion of trust in the social institutions that undergird democracy, as many citizens feel that their visibility and voice are losing political impact.

Yet parallel with these developments we also note a contrary narrative: we see a renewed engagement across the political spectrum, as an array of groups, mostly operating outside the confines of party politics but often trying to impact on legislation, enter the public sphere. The political stage is populated by many established single issue groups, temporary issue publics, lobbying outfits, NGO's, social movements, protest activists, citizen networks and other formations, active at local, regional, national and global levels. On other fronts, along side of - or instead of - traditional politics, many citizens are also exploring 'life-', 'identity-', and 'cultural' politics. Indeed, the realm of politics is transmuting, as citizens broaden the notion of what constitutes the political.

The frustrations of feeling marginalised or excluded, the sense that the established parties are insufficiently responsive, the strategic perception that pressure can be brought upon decision makers by other means - all these impulses contribute to the development of what Rosanvallon [12] terms counter-democracy, the process whereby citizens, in various constellations, exercise indirect democratic power by bypassing the electoral system. Engaged - and enraged - citizens in various modes of organisation from Greece to Great Britain, from the Middle East to the American mid-West, are finding alternative paths to the political in pursuit of their own interests 
or in their visions for better society, with varying degrees of impact. In these endeavours social media loom large.

\section{Social Media and Democratic Hopes}

At a general level, the web and its ancillary technologies such as mobile telephony have come to engender an ever more ubiquitous environment, where more and more people spend much of their time for an array of purposes. Especially people in the younger age cohorts are using the various affordances of those communication technologies in active and creative ways. The present online media landscape, often summarised under the rubric of Web 2.0, provides opportunities not only to send written and spoken words, but also to produce, upload, remix, link and share materials, in increasingly collaborative and complex ways.

The new cultural terrain is exciting but can also be confusing (Lovink [13]), as daily practices, identities, and relationships evolve. The web is not just something people 'visit' on occasion in order to seek something special, it is increasingly part of the terrain of their daily lives. Baym [14] offers a detailed analysis of how digital media's reach and capacities for interaction, their modes of social cues, their temporal structures, their mobility, and other features serve to facilitate social connections. From social interaction with friends to gossip blogging, from music perusals to news, from shopping to finding a partner, the web environment is becoming a taken-forgranted site where people's lives are increasingly embedded. It impacts on the strategies and tactics of everyday life and the frames of reference that provide them with meaning.

Turning specifically to social media, we should note that they are embedded in the larger web environment, which in turn is enveloped by the broader society at large, with its prevailing patterns of power, hierarchy, and ideological currents. Also, we can observe there are different genres of social media, and, ultimately, specific sites. Thus, any site does not operate in a vacuum, but is intricately woven into the political, economic, and cultural fabric of society and the web. Among the major genres, we can mention the most common forms: blogs are online journals, whose purposes, content, duration, and impact vary enormously; microblogs involve small scale content ('updates'), distributed online and via mobile phone networks, with Twitter as the obvious leader here; social networks like Facebook, allow people to generate personal web pages and to connect and share with others; content networks, organise and share particular kinds of content (legal as well as and illegal) - the largest is of course YouTube; wikis are websites where people to add and modify content collectively, generating a communal database, Wikipedia as the best known example; forums are areas for online discussion, usually focused on specific topics and interests; podcasts make audio and video files available by subscription, through services like Spotify and Apple iTunes.

In this sprawling webscape, there are distinctions worth taking into account. For example, wikis have mostly retained their basic open, communal character, and are predicated on trust and driven by the cooperative efforts of their uses. Blogs vary 
enormously, but the blog platforms are largely commercial products. Both YouTube and Facebook began as community sites, were bought by Google and have become commercial operations. Especially in the case of Facebook, as I discuss below, this has immense implications for participation.

An important positive attribute of all these forms is that they share is a capacity to facilitate horizontal communication: people and organizations can directly link up with each other for purposes of sharing information as well as affect, for providing mutual support, organizing, mobilizing, or solidifying collective identities. This feature makes them well-suited as civic media. Digital networks, with their polycentric nodes, offer a communication structure which can foster democratic social relations, as Castells [15] and Fenton [16] demonstrate, impacting on how civic agency is enacted and how politics gets done. It is important to underscore the social character of such activity: the networking involved helps to avoid the debilitating consequences of isolation, promotes social (and political) capital, and helps to forge collective identities. People continue to develop their civic practices in online settings as they find new ways to use these evolving communication technologies. The tools are more and more effective, less expensive, and easier to use than in the past; access and collaboration are increasing. Digital media are very good in helping to promote a subjective civic empowerment, an enhanced sense of agency.

The vision of the web's potential for extending and deepening democratic involvement is thus compelling. The vast universe of the web makes it easier for the political to emerge in online communication: politics can 'break out' unexpectedly and go viral. Who would have thought a few years ago that that materials from political demonstrations would be uploaded on YouTube, and that it, Facebook, and Twitter would become important institutions of the public sphere, facilitating debates and opinion formation?

Yet, such general enthusiasm must be the contingent character of online political participation. We have to reject all the cheery techno-optimism that avoids seeing social media in their social contexts, as part of the larger social and cultural world, intertwined with the offline lives of individuals as well as with the functioning of groups, organisations, and institutions of society (see Couldry [17] for an integrated sociological perspective). Since the mid-1990's, research has extensively explored this theme, as I have discussed elsewhere, in Dahlgren [18]. An ambivalent picture emerges. In this literature. For one thing, research indicates that using the web for political purposes (at least defined in traditional terms) comes quite far down on the list of activities, far behind consumption, entertainment, social connections, pornography, and so on. Today the opportunities for involvement in consumption and entertainment are overwhelmingly more numerous, more accessible, and more enticing for most people, compared to civic or political activities.

Even in public sphere contexts, we should bear in mind that the density of the web environment in the contemporary media landscape results in an enormous competition for attention, not least in regard to political affairs, that all web-based actors face; getting and holding an audience is no easy matter for most actors on the web. Also, while social media are impressive tools of historic dimensions, they does not, on their own, politically mobilise citizens who may lack engagement. (See the recent 
collections by Loader and Mercea [19] and by Feenberg and Freisen [20]). We must avoid reductionist thinking; policy discourses and journalistic commentary at times lead us astray in this regard, for example when the uprisings during the Arab Spring become simplistically framed as 'Twitter revolutions' (see more analytic views, see for instance, Communication Review [21] and Journal of Communication [22].

\section{Contingencies of Political Economy}

In using social media, we leave all sorts of electronic traces behind us. This kind of surveillance, the gathering and selling of private data, is a largely unseen - or at least often ignored - danger for democracy. It has troublesome implications not just for normative principles, but also for power relations. The features I discuss here are, so to speak, built into the architecture of the web, and its financial logic. This is not to make any essentialist argument about internet as a technology, but rather to highlightt how it is socially organised and used. The empowerment that the web does offer citizens is thus confronted by other relations of power in which citizens are rendered subordinate. These contradictions suggest continuous tensions of power and interests, an aspect we need to keep in view to understand the links between the web and democracy. An expansive treatment of this perspective is found in Fuchs [23].

As politics in society generally takes on a larger presence online, the prevailing structures of established power in society are increasingly mediated, solidified, negotiated and challenged via these media. I will exemplify the arguments by highlighting a few key elements in regard to the political economy of Google, then the surveillance and marketing mechanisms of Facebook.

\subsection{The Google Gameplan}

Google is not a part of social media, but it is such a behemoth on the web that the functioning of social media - and so much else - is profoundly affected by its activities, as Fuchs [24] and Vaidhyanatha [25] show. It has in a few short years become a decisive force in shaping how the web operates and what we can do with it (see Cleland and Brodky [26]). Moreover it has become the largest holder of information in world history, both public and private, shaping not only how we search for information, but also what information is available, how we organize, store, and use it. In many ways it is an utterly astounding development and has become a completely decisive feature of the net's architecture. For the year 2010, over 85 percent of all searches worldwide were carried out by Google; by comparison, its nearest competitor, Yahoo, accounted for just over six percent, as Fuchs [24] indicates. Google has also become a verb.

Locked into fierce competition with its competitors, especially Microsoft, on a number of fronts, Google established itself largely through the small text ads that accompany search results, but has grown into an enormous concentration of power that is largely unaccountable, hidden behind the cheery corporate motto 'Don't be Evil'. It has managed to generate considerable trust, but increasingly very serious 
questions are being raised, about copyrights and privacy, about how it is using its information, about Google's own agenda in striving to organize knowledge on a global scale, about its role in democracy. All this is not to detract from its truly impressive accomplishments; rather, the issue is that the position it has attained, and the activities it pursues (which are quite logical given its position), raise questions about information, democracy, accountability, and power in regard to the web.

Google has an overwhelming global monopoly of the search engine market. The company tends to prioritise certain sites at the expense of others, particularly favouring those that are backed by wealthy and powerful interests, thereby jeopardising the public and democratic character of the web, as Beer, [27] discusses. At the same time, it denies transparency in regard to, for example, its PageRank algorithm and Googlescholar search process. It is now moving into other areas such as academic books, posing new threats to the democratic nature of knowledge.

Further, and perhaps most significant from the standpoint of participation, Google engages in surveillance and privacy invasion of citizens in the gathering of consumerrelated data. The personal electronic traces are gathered up, stored, sold, and used for commercial purposes. This is done with our formal consent, but often via discrete, friendly strategies. And if we refuse, we effectively cut ourselves off from the major utilities of the web. As Goldberg [28] suggests, all participation on the net, even the most radical political kind, feeds data into the commercial system that is its infrastructure. The more people spend time online, the more Google's economic power is enhanced. What happens with all the surveillance data routinely gathered on us? Turow [29] shows how new kinds of high tech marketing and adverting firms integrate and analyse personal data from many sources in order to develop individual and household profiling and media customization - much of it channeled through social media. This not only undermines much the rhetoric about consumer power and initiative - we are decidedly not in the drivers' seat here, but rather at the receiving end of carefully planned strategies to offer us products and services the marketers think we should have, based on our profiles. On a deeper level, this kind of profiling of course has even more troubling ramifications, since with only a slight change in circumstances it can have consequences for our political freedom as well.

While Google presents an image of itself as a flat, decentralized organization, it acts as an extreme force for centralization, ideologically camouflaged by a technodeterminist discourse that asserts that the solution to society's problems lies in information technology - and not in, for example, in dealing with unaccountable power in the private sector. Its cooperation with the Chinese government between 2005 and 2010 in censoring politically sensitive search words also puts in question its commitments to democracy. Society benefits immensely from what Google has accomplished, but these problematic costs to democracy tend to be deflected from view. The prevailing neoliberal climate has made it harder to confront this private enterprise with demands about the public good, and the global character of its operations renders all the more difficult any attempts at national regulation. What is ultimately required, as MacKinnon [30] argues, is a global policy that can push regulation of the web such that it will treated like a democratic, digital commons; we have a long way to go. 


\subsection{What a Friend We Have in Facebook}

It may well be that the daily socialisation to not reflect on these issues that can prove to be most significant in the long term. Discipline works largely by establishing patterns of thought and behavior, and can be seen as a power-driven form of socialization. While we cooperate indirectly with Google in providing personal information, with Facebook it becomes much more explicit, and here we should no doubt be more even concerned about what kind of information about ourselves we are making available to whom, as Dwyer [31] underscores.

In Facebook's role as a site for political discussion, one can reflect on the implications of the familiar mechanism of 'like': one clicks to befriend people who are 'like' oneself, generating and cementing networks of like-mindedness. As time passes, and people increasingly habituate themselves to encountering mostly people who think like they do, and as sustained debate evaporates, we can postulate on the danger to democracy. The social logic is that citizens lose the capacity to discursively encounter different views; the art of argument erodes, and deep differences to one's own views ultimately become seen as expressions of the irrational. Time will tell; meanwhile we have the very immediate issues of surveillance and privacy on Facebook.

Facebook, with now over 800 million users, compiles massive amounts of data on individuals, largely freely given (in this discussion I borrow considerably from Grimmelmann [32]. A full Facebook profile contains about 40 pieces of personal information, with a variety of tools available for users to search out and add potential contacts. The so-called Wall posts can convey personal information about the poster. The payment mechanisms for Gifts generates strong links between a profile and offline identities. To upload and tag a Photo of yourself documents your appearance; it also documents that the photographer knows the person photographed. And there is more: each game of Scrabulous one plays gives some a sense of one's vocabulary; one's list of Causes tells others what principles are meaningful to you; answering a Quiz reveals one's knowledge, beliefs, and preferences. And so on.

The interesting question sociologically is why so many people trust Facebook with so much personal information. Basically it has to do with the fact that people have very social reasons for joining social network sites. They gain social connections, and the sites become forums for developing identities and social capital. These are strong motivations and can explain at least in part why so many users tend to ignore the rather well-known risks to their privacy. The sense of collective identity suggests that we are basically alike and thus we are in this together. An element of group think may say that since everyone else is doing it, it must be safe, and if collectively define this as private, well then, it must be private. This can be seen as a case of misplaced trust.

\section{Socio-cultural Currents}

\section{$5.1 \quad$ Social Imaginaries}

Castoriadis [33] makes use of the notion of the social imaginary, which he takes to be the overarching collective meanings in society anchored in repetitive representations, 
affect, intentions and will. One could also call them ideological motifs, or hegemonic discourses, depending on which theoretic tradition one prefers, but the basic idea is that social imaginaries permeate society, providing frameworks for making sense of the world and one's place in it. They serve to adjust not only our perceptions of external reality but also our inner subjective dispositions; they have political import. Straume [34] uses the concept to map the elements that comprise the key ideational horizons of neoliberal global economic system from the standpoint of the social world. Not surprisingly, she pinpoints such themes as a sense of never-ending economic growth, freedom, rationality, an absence of serious environmental concern, consumerism, a sense of privatized fulfillment, and a stance of non-interference in market mechanisms. The basic relationship of the individual to economic society is characterized by she calls depoliticisation. A number of these themes are familiar from the discussions above, and no doubt from other directions as well: they comprise much of the prevailing discursive currents of contemporary society and are by no means unique for the web, even if their online manifestations take particular forms of expression.

These currents of the social imaginary, while seemingly abstract, manifest themselves in concrete circumstances in the symbolic worlds of our everyday lives. We should be wary of reducing the wide range of political expression visible today at times positively cacophonic - to just positions that support or criticize the dominant economic arrangement, but the themes of this prevailing current comprise an important referent for the fundamental health of democracy. Depoliticisation, the avoidance of the political, is as we can recall, one of the dilemmas in fact confronting democracy, and one that is challenged by the current waves of counter-democracy. Often they involve positioning us as consumers rather than citizens.

Significantly, these elements in the major currents of the social imaginary do not operate only at the level of formal ideas, but are embodied in many forms of expression from popular culture to journalism, from street humour to self-help therapies. Similarly, alternative politics does not manifest itself only as coherent political statements, but can be implied in televised satire (e.g. The Daily Show with Jon Stewart), manifested in the performance of rap lyrics, in social critique embedded in detective fiction, or evoked via expressions of solidarity and care for marginalized groups, and so on. Thus, while the coherent articulation of ideas still remains central to political life, political sentiments in the form of dominant and oppositional social imaginaries are increasingly embedded in various modes of cultural expression and resonate in the subjective realm of affect.

\subsection{The Web Environment and Subjective Experience}

If we transpose these thoughts to the online environment, it means that we should examine how the hegemonic and contested currents find expression in the Web 2.0 milieu, and we can assume that these currents are driven by both rational and affective elements, with the latter seemingly on the ascent. Media culture generally overall seems to be moving every further away from the ideals of the traditional public sphere and its rational character. As Lievrouw [35] aptly describes the situation: 
Media culture in the digital age has become more personal, skeptical, ironic, perishable, idiosyncratic, collaborative, and almost inconceivably diversified, even as established industries and institutions seek to maintain their grip on stable messages and audiences and to extend their business models online (p.214)

What she captures here in fact is some of the definitive textures of the late modern situation, with their cross-currents of power relations and their particular sensibilities and affect. It is against this historical backdrop, as I indicated earlier, that we have to understand contemporary political participation. Lievrouw's analysis underscores the interplay between the affordances of communication technologies and the practices by which people utilise them for their own purposes. They 'construct new meanings and expressions out of existing and novel forms of interaction, social and institutional relationships, and cultural works' (Lievrouw [35], p. 216). This perspective helps us to understand more concretely how hegemonic and contested social imaginaries are embedded and played out in social media, in particular where our potential identities as citizens are all too often overwhelmed by socio-cultural forces that position us as consumers.

Commentators of the web have coined the terms 'cocoons' and 'echo chambers' to signify the tendency for people to group themselves into networks of likemindedness. This is of course an understandable human behavior pattern - one avoids conflicts and gets one's one world views and values reinforced. Socially it makes a lot of sense. But for democracy there is a danger: these public 'sphericles' tend to isolate its members from larger discursive flows within political society. Moreover, they also serve to reduce their participants' experiences with confronting alternative points of view, as well as their competence in engaging in argument. Let us recall Facebook's click logic and how it encourages enclaves of like-mindedness.

\subsection{In the Shadow of the Solo Sphere}

A further online pattern that seems to be emerging and which is worrisome in regard to participation and the culture of democracy, is a form of personalised visibility that engages in self-promotion and self-revelation. When (especially) younger people do turn to politics, it seems that these patterns of digital social interaction increasingly carry over into the political realm. Papacharissi [36] argues that while digitally enabled citizens may be skilled and reflexive in many ways, much civic behavior today has its origins in private environments, which she suggests is giving rise to a new 'civic vernacular'. I think this analysis is definitely on the right track, but while she labels this setting for political engagement as the private sphere, it seems to me that this may term may be misleading. It readily evokes the traditional, cozy family or home milieu. This is no doubt a part of the setting, but I would call it instead the solo sphere, to indicate its historically new character. The solo sphere can be seen as a historically new habitus for online political participation, a new platform for civic agency.

From the networked and often mobile enclosures of this personalized space, the individual engages with a vast variety of contexts in the outside world. It may well be 
that the online setting, with its powerful technical affordances, discourages engagement beyond itself. Papacharissi [36] suggests that it fosters a retreat into an environment that many people feel they have more control over; a networked yet 'privé sociality' emerges. We can add that this also suggests that 'networks', necessary and always potentially of use, are not by themselves inherently mobilizing or liberatory. Thus, these feature introduces an historically new contingency for participation - which may in turn signal a historically new kind of democratic system. Yet we need not spend too much time with the crystal ball trying to predict the future; there is plenty to do in the present.

\section{The Challenge of Participation: Modest Hopes}

I have argued for here for the importance of the fundamental perspective of contingency so that we can better grasp the possibilities and limitations of social media for counter-democratic political participation. Analytically one can specify a broad array of contingencies. I have only touched upon some of the major ones, in the form of the political economy and architecture, as well as socio-cultural currents. It is in the analysis of the interwoven, configurational lines of influence of these and other such factors that we can begin to grasp the dynamics at work. At present, despite the problematic political circumstances and many uncertainties, the historical future for democracy still remains open. Counter-democratic participation, though seriously challenged, still hovers within reach and is enacted by many citizens. Social media are indispensible - but not politically decisive on their own. Research needs to continue to probe this complex relationship in order to better analytically understand - and enhance - participation.

\section{References}

1. Agamben, G., et al.: Democracy in What State? Columbia University Press, New York (2011)

2. Harvey, D.: A Brief History of Neoliberalism. Oxford University Press, Oxford (2006)

3. Harvey, D.: The Enigma of Capital and the Crises of Capitalism. Profile Books, London (2011)

4. Fisher, M.: Capitalist Realism: Is There No Alternative? Zero Books, Ropley (2009)

5. Bauman, Z.: Collateral Damage: Social Inequalities in a Global Age. Polity Press, Cambridge (2011)

6. Sandel, M.: What Money Can't Buy: The Moral Limits of Markets. Allen Lane, London (2012)

7. Couldry, N.: Why Voice Matters: Culture and Politics After Neoliberalism. Sage, London (2010)

8. Lewis, J.: Crisis in the Global Mediasphere: Desire, Displeasure and Cultural Transformation. Basingstoke, Palgrave (2011)

9. Young, J.: The Vertigo of Late Modernity. Sage, London (2007)

10. Bauman, Z.: Liquid Times: Living in an Age of Uncertainty. Polity Press, Cambridge (2007)

11. Crouch, C.: The Strange Non-Death of Neoliberalism. Polity Press, Cambridge (2011) 
12. Rosanvallon, P.: Counter-Democracy: Politics in an Age of Distrust. Cambridge University Press, Cambridge (2008)

13. Lovink, G.: Networks Without a Cause: A Critique of Social Media. Polity, Cambridge (2011)

14. Baym, N.K.: Personal Connections in the Digital Age. Polity Press, Cambridge (2010)

15. Castells, M.: Communication Power. Oxford University Press, Oxford (2010)

16. Fenton, N.: The Internet and Social Networking. In: Curran, J., Fenton, N., Freedman, D. (eds.) Misunderstanding the Internet, pp. 123-148. Routledge, Abington (2012)

17. Couldry, N.: Media, Society, World: Social Theory and Digital Media Practice. Polity Press, Cambridge (2012)

18. Dahlgren, P.: Media and Political Engagement. Cambridge University Press, New York (2009)

19. Loader, B., Mercea, D. (eds.): Social Media and Democracy. Routledge, Abingdon (2012)

20. Feenberg, A., Freisen, N. (eds.) (Re)inventing the Internet: Critical Case Studies. Sense Publishers, Rotterdam (2012)

21. The Communication Review: Special Issue: Twitter Revolutions? Addressing Social Media and Dissent. 14(3) (2011)

22. The Journal of Communication: Special Issue: Social Media and Political Change 62(2) (2012)

23. Fuchs, C.: Foundation of Critical Media and Information Studies. Routedge, Abington (2011)

24. Fuchs, C.: A Contribution to the Critique of the Political Economy of Google. FAST CAPITALISM 8.1 (2011), http: / / www. fastcapitalism.com

25. Vaidhyanatha, S.: The Googlization of Everything (And Why We Should Worry). University of California Press, Berkeley (2011)

26. Cleland, S., Brodky, I.: Search and Destroy: Why You Can't Trust Google. Telescope Books, St. Louis (2011)

27. Beer, D.: Power Through the Algorithm? Participatory Web Cultures and the Technological Unconscious. New Media and Society 11(6), 985-1002 (2009)

28. Goldberg, G.: Rethinking the Public/Virtual Sphere: The Problem with Participation. New Media and Society 13(5), 739-754 (2010)

29. Turow, J.: The Daily You: How the New Advertising Industry is Defining Your Identity and Your Worth. Yale University Press, New Haven (2011)

30. MacKinnon, R.: Consent of the Networked: The Worldwide Struggle for Internet Freedom. Basic Books, New York (2012)

31. Dwyer, T.: Net worth: Popular Social Networks as Colossal Marketing Machines. In: Sussman, G. (ed.) Propaganda Society: Promotional Culture and Politics in Global Context, pp. 77-92. Peter Lang, New York (2010)

32. Grimmelmann, J.: Facebook and the Social Dynamics of Privacy (August 25, 2008), http://www.ciberdemocracia.es/recursos/textosrelevantes/ facebook.paf

33. Casrtoriadis, C.: Psychoanalysis and Philosphy, id, The Casatoriadis Reader. Blackwell, Oxford (1997)

34. Straume, I.: The Political Imaginary of Global Capitalism. In: Straume, I.S., Humphrey, J.F. (eds.) Depoliticization: The Political Imaginary of Global Capitalism, pp. 27-50. NSU Press, Malmö (2011)

35. Lievrouw, L.A.: Alternative and Activist New Media. Polity Press, Cambridge (2011)

36. Papacharissi, Z.: A Private Sphere: Democracy in a Digital Age. Polity Press, Cambridge (2010) 